\title{
Exploratory study of the relationship of fat-free mass to speed of brain processing in preterm infants
}

\author{
Katie M. Pfister ${ }^{1}$, Heather L. Gray ${ }^{2}$, Neely C. Miller ${ }^{3}$, Ellen W. Demerath ${ }^{2,3}$, Michael K. Georgieff ${ }^{1,3}$ and Sara E. Ramel ${ }^{1,3}$
}

BACKGROUND: Preterm infants are at risk for long-term neurodevelopmental impairment as a function of postnatal nutritional status. Despite adequate neonatal weight gain, preterm infants have altered body composition, with lower fat-free mass (FFM) and higher adiposity at term corrected gestational age (CGA) than their term counterparts. The relationship between postnatal body composition and speed of brain processing in preterm infants is unknown.

METHODS: Anthropometric measurements and body composition testing via air displacement plethysmography were performed on 16 appropriate-for-gestational age (GA) preterm (mean GA: 30.4 $\pm 2.8 w k$ ) infants at term and 4 mo CGA. Infant visual pathway development was assessed at 4 mo CGA using pattern-reversal visual evoked potential (VEP); P100 (positive peak) latency was used to index neuronal speed of processing. RESULTS: Increased FFM at discharge $(P=0.02)$ and 4 mo CGA $(P=0.006)$ was associated with shorter latencies to the P100 peak. P100 latency was not related to total body weight, fat mass, or body fat percentage.

CONCLUSION: FFM reflects protein accretion and indexes growth of organs, including the brain. The association of shorter VEP latency (i.e., faster neuronal processing) with higher FFM (i.e., better protein status) may be attributed to the positive effects of protein status on neuronal growth and differentiation.

$\mathbf{P}$ reterm infants are at risk for long-term neurodevelopmental delays and impairment as a function of postnatal nutritional status and growth, which includes gains in weight, head circumference, and length (1-5). Recommendations have been made for postnatal growth and body composition of lowbirth-weight infants to mimic those of the fetus to decrease the negative influence of poor nutrition on neurodevelopmental outcomes (6). However, although aggressive nutritional management has resulted in less failure to achieve weight goals (7), preterm infants continue to have altered body composition characterized by lower fat-free mass (FFM) and relatively increased adiposity at term corrected gestational age (CGA) compared with their term counterparts $(8,9)$. Moreover, they demonstrate significant linear growth suppression (i.e., stunting) that continues at least $2 y$ beyond hospital discharge (3).

Early neonatal growth in weight, length, and head circumference is positively associated with neurodevelopmental outcomes
$(1,3,10)$. FFM gains and linear growth are important because they index growth and development of the organs, including the brain (11). They also reflect protein accretion (12), and the brain is highly reliant on protein for neuronal growth and differentiation (13). Higher protein intake early in the postnatal life of preterm infants correlates with increased length and head circumference at term (14) and is associated with higher developmental scores at $18 \mathrm{mo}$ (15). Furthermore, linear stunting has been implicated in poorer neurodevelopmental outcomes in this population (3) and others $(16,17)$. Therefore, body composition (specifically FFM) could indirectly assess brain development and processing early in development.

One aspect of brain development that is likely to be affected by stunting is speed of neuronal processing, which reflects processes such as synaptic efficacy and myelination. It can be assessed in neonates with visual evoked potentials (VEPs), which are EEG recordings that are time-locked to a specific visual stimulus, thus representing the brain's response to that visual stimulus. The component of interest in a VEP is the P100 (named for its positive peak occurring $100 \mathrm{~ms}$ after the stimulus onset). The latency to the peak of the P100 represents speed of neural processing and maturation of the visual system (18). VEPs are easily recorded and the P100 waveform has low intrasubject variability. During the last trimester of gestation and the first several months of life, the visual pathway develops rapidly, which is reflected by significant changes in the VEP. As the brain develops, latency to the P100 peak decreases from 250 to $300 \mathrm{~ms}$ at term to $\sim 100 \mathrm{~ms}$ by $6 \mathrm{mo}$ in normal infants (18). Therefore, VEPs can be used to give some insight into early postnatal brain development and provide a clearer linkage between neonatal risk factors and brain function.

The objective of this study was to assess the relationship between postnatal body composition and brain development as indexed by latency to the P100 peak of the VEP in preterm infants measured at 4 mo corrected age.

\section{RESULTS}

Infant Characteristics

Sixteen out of the 26 infants who underwent body composition assessment had acceptable VEP data. There was a significant difference in birth weight (1,531 vs. $2,031 \mathrm{~g}, P=0.03$ ), birth occipital frontal circumference (OFC; 28.3 vs. $30.9 \mathrm{~cm}, P=0.007)$, and 
Table 1. Descriptive characteristics of 16 appropriate-for-gestational age preterm infants

\begin{tabular}{|c|c|c|}
\hline & Mean (SD) & Range \\
\hline \multicolumn{3}{|l|}{ Infant } \\
\hline Gestational age, wks & $30.39(2.79)$ & $26.29-34.86$ \\
\hline Sex, male, $N(\%)$ & $8(50.0)$ & - \\
\hline Energy deficit, $\mathrm{kcal}^{\mathrm{a}}$ & $94.12(63.41)$ & $17.83-230.56$ \\
\hline Protein deficit, $\mathrm{g}^{\mathrm{b}}$ & $1.92(2.54)$ & -2.59 to 5.93 \\
\hline Score for neonatal acute physiology & $10.63(7.67)$ & $3.0-35.0$ \\
\hline Retinopathy of prematurity, yes, $N, \%^{c}$ & $4(25.0)$ & - \\
\hline Abnormal neuroimaging, yes, $\mathrm{N}, \%^{\mathrm{d}}$ & $1(6.25)$ & - \\
\hline Antenatal steroids, yes, $N, \%$ & $14(87.5)$ & - \\
\hline Postnatal steroids, yes, $N, \%$ & $4(25.0)$ & - \\
\hline \multicolumn{3}{|l|}{ Birth } \\
\hline Weight, kg & $1.53(0.59)$ & $0.81-2.89$ \\
\hline Weight, z score & $-0.07(0.54)$ & -0.81 to 1.35 \\
\hline Length, $\mathrm{cm}$ & $40.5(5.41)$ & $33.5-49.0$ \\
\hline Length, $z$ score & $0.09(1.21)$ & -2.00 to 1.90 \\
\hline $\mathrm{OFC}, \mathrm{cm}$ & $28.26(3.00)$ & $23.5-32.5$ \\
\hline OFC, zscore & $0.17(0.68)$ & -0.80 to 1.40 \\
\hline \multicolumn{3}{|l|}{ Visit 1} \\
\hline Corrected age, weeks & $40.86(0.76)$ & $39.29-41.86$ \\
\hline Weight, kg & $3.36(0.40)$ & $2.71-4.14$ \\
\hline Weight, z score & $-0.18(0.78)$ & -1.79 to 0.87 \\
\hline Length, $\mathrm{cm}$ & $50.24(2.33)$ & $46.10-53.40$ \\
\hline Length, $z$ score & $-0.26(1.22)$ & -2.76 to 1.60 \\
\hline $\mathrm{OFC}, \mathrm{cm}$ & $36.08(1.01)$ & $34.00-37.55$ \\
\hline OFC, z score & $1.00(0.86)$ & $-0.98-2.43$ \\
\hline Fat-free mass, kg & $2.73(0.33)$ & $2.21-3.41$ \\
\hline Fat mass, kg & $0.62(0.14)$ & $0.30-0.87$ \\
\hline Body fat, $\%$ & $18.53(3.63)$ & $10.10-24.80$ \\
\hline Any breastfeeding, yes, $N, \%$ & $12(75.0)$ & - \\
\hline \multicolumn{3}{|l|}{ Visit 2} \\
\hline Corrected age, weeks & $59.12(1.77)$ & $55.86-62.43$ \\
\hline Weight, kg & $6.40(0.82)$ & $5.26-8.25$ \\
\hline Weight, z score & $-0.71(1.04)$ & -2.46 to 1.12 \\
\hline Length, $\mathrm{cm}$ & $62.97(2.90)$ & $57.10-68.50$ \\
\hline Length, $z$ score & $-0.40(1.20)$ & -2.18 to 1.66 \\
\hline $\mathrm{OFC}, \mathrm{cm}$ & $42.31(1.22)$ & $40.00-44.00$ \\
\hline OFC, z score & $0.67(0.85)$ & -1.21 to 1.95 \\
\hline Fat-free mass, kg & $4.83(0.58)$ & $3.89-5.99$ \\
\hline Fat mass, kg & $1.57(0.43)$ & $0.84-2.26$ \\
\hline Body fat, $\%$ & $24.31(5.19)$ & $13.60-30.80$ \\
\hline Any breastfeeding, yes, $N, \%$ & $6(37.5)$ & - \\
\hline \multicolumn{3}{|l|}{ Maternal } \\
\hline Age, years & $29.81(4.49)$ & $21.0-38.0$ \\
\hline Race, white, $N, \%$ & $15(93.8)$ & - \\
\hline Education, >high school, $N, \%$ & $10(62.5)$ & - \\
\hline
\end{tabular}

Table 1. Continued

\begin{tabular}{lll} 
& \multicolumn{1}{c}{ Mean (SD) } & \multicolumn{1}{c}{ Range } \\
\hline Paternal & & \\
Age, years & $32.63(4.95)$ & $23.0-41.0$ \\
Race, white, $N, \%$ & $13(81.3)$ & - \\
Education, $>$ high school, $N, \%$ & $10(62.5)$ & - \\
\hline
\end{tabular}

OFC, occipital frontal circumference; ROP, retinopathy of prematurity.

Data are expressed as mean SD for continuous variables or $n$ (\%) for categorical variables.

aEnergy deficit calculated by using $120 \mathrm{kcal} / \mathrm{kg} / \mathrm{d}$ goal and subtracting or adding the actual amount of energy received. ${ }^{b}$ Protein deficit calculated by using $3.5 \mathrm{~g} / \mathrm{kg} / \mathrm{d}$ goal and subtracting or adding the actual amount of protein received. Two infants had stage 2 ROP, and two infants had stage 1 ROP. None required intervention. ${ }^{\mathrm{d} O n e ~ i n f a n t ~}$ had grade 2 intraventricular hemorrhage, which resolved.

birth gestational age (GA; 30.4 vs. $33.2 \mathrm{wk}, P=0.009)$ between the accepted vs. rejected infants, respectively. There was no significant difference in birth weight, length, or OFC $z$-scores; FFM, weight, length, or OFC at either visit; sex; caloric, or protein deficit during hospitalization; Score for Neonatal Acute Physiology (SNAP) value; or parental age or education level between the infants with acceptable and inadequate VEP data (and who were, therefore, excluded). Infant characteristics at birth, visit 1 , and visit 2 , in addition to parent characteristics of infants with acceptable data, are presented in Table 1.

\section{Relationship of Infant Body Composition at Term and 4 mo CGA With P100 Latency at 4 mo CGA}

Table 2 shows the association of anthropometrics and body composition with latency to the P100 peak. When controlling for infant sex (Model 1), higher weight, length, and FFM at both term CGA and 4 mo CGA were significantly associated with shorter $P 100$ latencies $(P$ values $\leq 0.04)$ at 4 mo CGA. Infant sex plus FFM account for $49 \%\left(r^{2}\right)$ of variance of P100 latency at visit 1 and $57 \%$ of the same at visit 2 . Infant sex plus weight accounts for 43 and $47 \%$ of variance of P100 latency at visit 1 and visit 2, respectively. Infant sex and length account for $46 \%$ of variance of P100 latency at visit 1 and $51 \%$ of variance at visit 2 . An illustration of the variation in timing of the VEP peak between two infants with differing FFMs can be seen in Figure 1.

With the addition of CGA at visit as a covariate (Table 2, Model 2), weight, FFM, and length at both visits remain significantly associated with the latency to the P100 peak. Approximately $45-60 \%$ of the variance of P100 latency is accounted for by these factors (infant sex, CGA at visit, and one among FFM, weight, or length). With the addition of GA at birth as a covariate in Model 3 (Table 2), higher FFM at 4 mo is also significantly associated with shorter latency to theP 100 peak $(P=0.04)$, and weight and length approach significance $(P=0.07$ and $P=0.1$, respectively). At visit 1 in Model 3, the association between higher FFM and faster latency also approaches significance $(P=0.1) . R^{2}$ values remain $48-60 \%$ for FFM, weight, and length in this model. In evaluating the influence of birth GA on P100 latency, when all other variables are constant at their referent values, for every week increase in 
Table 2. Association of anthropometrics and body composition with latency to P100 wave (average of sensors 32, 33, 36, 37, 38, 40, 41, and 45) at term and 4 mo corrected age

\begin{tabular}{|c|c|c|c|c|c|c|c|c|}
\hline & \multicolumn{2}{|c|}{ Unadjusted model } & \multicolumn{2}{|c|}{ Model 1} & \multicolumn{2}{|c|}{ Model 2} & \multicolumn{2}{|c|}{ Model 3} \\
\hline & $\beta$ (SE) & $P$ & $\beta(\mathrm{SE})$ & $P$ & $\beta(\mathrm{SE})$ & $P$ & $\beta(\mathrm{SE})$ & $P$ \\
\hline \multicolumn{9}{|l|}{ Visit 1} \\
\hline Weight, kg & $-18.08(19.11)$ & 0.36 & $-42.98(16.96)$ & 0.02 & $-43.59(18.00)$ & 0.03 & $-33.71(20.100$ & 0.12 \\
\hline Length, $\mathrm{cm}$ & $-4.90(3.08)$ & 0.13 & $-6.06(2.67)$ & 0.04 & $-6.65(2.96)$ & 0.04 & $-4.82(3.64)$ & 0.21 \\
\hline $\mathrm{OFC}, \mathrm{cm}$ & $2.08(7.68)$ & 0.79 & $-9.62(8.72)$ & 0.29 & $-9.47(9.10)$ & 0.32 & $-12.20(7.97)$ & 0.15 \\
\hline Fat-free mass, $\mathrm{kg}$ & $-31.16(22.08)$ & 0.18 & $-51.27(18.59)$ & 0.02 & $-52.27(19.76)$ & 0.02 & $-41.75(23.16)$ & 0.10 \\
\hline Fat mass, kg & $28.02(54.01)$ & 0.61 & $-12.56(57.72)$ & 0.71 & $-21.05(59.94)$ & 0.73 & $-19.21(54.67)$ & 0.73 \\
\hline Body fat, $\%$ & $2.50(2.04)$ & 0.24 & $1.51(2.06)$ & 0.48 & $1.48(2.15)$ & 0.50 & $0.76(2.03)$ & 0.71 \\
\hline \multicolumn{9}{|l|}{ Visit 2} \\
\hline Weight, kg & $-10.04(9.07)$ & 0.29 & $-20.30(7.88)$ & 0.02 & $-20.64(7.56)$ & 0.02 & $-25.95(12.71)$ & 0.07 \\
\hline Length, $\mathrm{cm}$ & $-2.82(2.58)$ & 0.29 & $-6.37(2.22)$ & 0.01 & $-5.99(2.31)$ & 0.02 & $-6.81(3.73)$ & 0.10 \\
\hline $\mathrm{OFC}, \mathrm{cm}$ & $1.52(6.40)$ & 0.70 & $-9.56(7.41)$ & 0.22 & $-10.23(7.26)$ & 0.18 & $-10.64(6.74)$ & 0.14 \\
\hline Fat-free mass, kg & $-8.17(13.17)$ & 0.55 & $-40.23(12.10)$ & 0.006 & $-38.24(12.49)$ & 0.01 & $-45.01(19.03)$ & 0.04 \\
\hline Fat mass, kg & $-21.45(17.03)$ & 0.22 & $-19.05(15.89)$ & 0.25 & $-25.12(15.58)$ & 0.13 & $-15.82(21.03)$ & 0.47 \\
\hline Body fat, $\%$ & $-1.50(1.45)$ & 0.32 & $-0.66(1.49)$ & 0.67 & $-1.48(1.55)$ & 0.36 & $-0.61(1.68)$ & 0.72 \\
\hline
\end{tabular}

OFC, occipital frontal circumference.

Model 1 includes the covariate sex. Model 2 includes covariates sex and corrected age at visit. Model 3 includes covariates sex, corrected age at visit, and gestational age at birth.

birth GA, there was a 1.7-ms increase in latency, which was not significant $(P=0.6)$.

When controlling for GA at birth, CGA at visit, and FFM, females had faster VEP latencies than males $(P=0.02)$. The least squared means for males was $199 \mathrm{~ms}$ and for females, it was $139 \mathrm{~ms}$ at 4 mo CGA.

Relationship of Infant Body Composition at Term and 4 mo CGA With P100 Peak Amplitude at 4 mo CGA

The association of body composition with peak amplitude of P100 was analyzed using the same models and covariates as in Table 2. There were only two statistically significant correlations: higher body fat percentage at visit 1 was associated with higher peak amplitude of P100 $(P=0.02$ in the unadjusted model and $P=0.05$ in Model 2).

\section{Relationship of Clinical Features With P100 Latency}

To explore the relationship of clinical factors as potential confounders of the body composition-brain development relationship, we examined the partial correlations between energy deficit, protein deficit, and illness score (SNAP) with latency to the P100 wave. Greater energy deficit was associated with shorter latency $(P=0.02)$. However, protein deficit and SNAP were not associated with P100 latency.

Infants who received postnatal corticosteroids had significantly longer latency to P100 (206 ms (steroids) vs. $159 \mathrm{~ms}$ (no steroids); $P=0.001$ ), as did infants who had retinopathy of prematurity (ROP; $198 \mathrm{~ms}$ (ROP) vs. $160 \mathrm{~ms}$ (no ROP); $P=$ 0.02 ). We were unable to analyze the difference in latency in infants with or without abnormal neuroimaging because there was only one infant with an abnormality (intraventricular

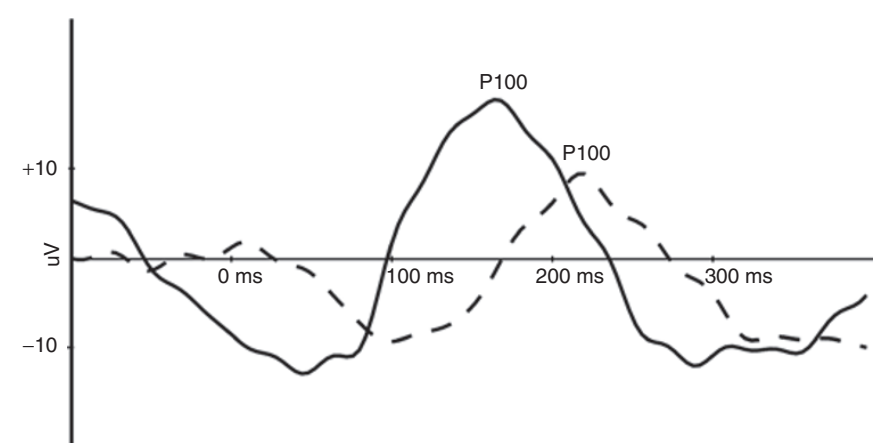

Figure 1. Grand mean VEP waveforms of an infant with relatively low FFM at both visits ( $2.3 \mathrm{~g}$ at visit 1 and $4.39 \mathrm{~g}$ at visit 2; dashed line) vs. an infant with a relatively high FFM at both visits $(3.03 \mathrm{~g}$ at visit 1 and $5.56 \mathrm{~g}$ at visit 2; solid line). FFM, fat-free mass; VEP, visual evoked potential.

hemorrhage). There was no significant difference in P100 latency in infants who received breast milk vs. no breast milk (at visit 1: $166 \mathrm{~ms}$ (breast milk) vs. $188 \mathrm{~ms}$ (no breast milk), $P=$ 0.32 ; and at visit 2: $161 \mathrm{~ms}$ (breast milk) vs. $175 \mathrm{~ms}$ (no breast milk), $P=0.38$ ). There was also no difference in P100 latency between infants whose mothers received antenatal steroids compared with those who did not (171 vs. 163 ms, respectively; $P=0.39)$.

\section{DISCUSSION}

Long-term neurodevelopmental outcomes of preterm infants are, in part, a result of nutritional status and growth in the postnatal period (1-5). Despite implementation of nutritional guidelines that aim to have weight and body composition of the preterm infant equivalent to its in utero counterpart, 
we and others have shown that body composition at term CGA remains different from that of a term newborn $(8,9)$, and linear growth remains stunted at least $2 \mathrm{y}$ beyond hospital discharge (3). Our study shows that variation in brain development of preterm infants, specifically speed of processing, can be detected as early as 4 mo CGA. This is important for linking brain status with specific neonatal events rather than potential postdischarge confounders because most studies that report neurodevelopmental outcomes of preterm infants make assessments at 18-24 mo or later by gross evaluation of development. Therefore, electrophysiologic techniques allow for evaluation of earlier, more specific (nutritional and nonnutritional) interventions while the system is relatively more amenable to treatment.

This study found that higher FFM, weight, and length at term and at 4 mo CGA are associated with shorter P100 latency (i.e., faster neuronal processing) at 4 mo CGA. By contrast, speed of processing was not related to OFC, fat mass, or body fat percentage at either time point. Therefore, it is not a high proportion of lean body mass that is associated with faster neuronal processing but a greater absolute value of FFM. Accordingly, a small, lean baby would have slower processing than a large, less lean baby if the larger baby has a grossly higher FFM. This is in agreement with the literature that good catch-up growth (1-5) and early protein initiation improve neurodevelopmental outcomes (15). FFM and length index growth and development of organs, including the brain (11), and reflect protein accretion (12). In addition, protein deficit is negatively associated with FFM in preterm infants (8), and higher protein intake during the first week of life in preterm infants is associated with higher developmental scores at 18 mo (15). Aggressive nutritional management of preterm infants (through early initiation of parenteral protein) also correlates with higher length and head circumference, in addition to higher levels of insulin-like growth factor-1 (IGF-1) and insulin-like growth factor binding protein-3 (IGFBP3), at $40 \mathrm{wk}$ CGA compared with conventional nutritional management (14). The association of faster latency to P100 with higher FFM (i.e., better protein status) could be explained by the positive effects of protein intake on protein accretion and thus on neuronal differentiation. This may include a direct effect of both providing necessary amino acids for dendrite structure and stimulating the synthesis of important neural growth factors such as IGF-1 and brainderived neurotrophic factor.

Growth factors, especially IGF-1, are important for neuronal growth and differentiation, including neurogenesis, synaptogenesis, and dendritic arborization (13). IGF-1 is nutritionally regulated, and animal studies have shown that protein restriction greatly decreases serum IGF-1 levels $(19,20)$ and modestly decreases brain tissue levels of IGF-1 (20). Growth factors mediate neuronal growth in part through the mammalian target of rapamycin pathway via PI3K signaling. Branched-chain amino acids also stimulate this pathway directly. The mammalian target of rapamycin pathway determines actin polymerization, neuronal growth, and survival (21). Furthermore, protein deficit is associated with decreased neurotransmitter production, growth factor synthesis, synapse number, and myelin (13), all of which are important for rapid neurotransmission. Although our data did not show a direct correlation between protein deficit and speed of neuronal processing, protein intake does not always closely correspond with protein accretion. For example, protein losses, which vary as the rate of catabolism varies, and energy intake influence protein accretion (22). Rates of catabolism in turn are a function of degree and duration of illness. In particular, inflammatory states (e.g., infection) and the use of corticosteroids increase protein breakdown. Unlike simple measurements of protein intake, the assessment of FFM does reflect protein accretion (12) and did correlate with speed of processing in our study.

The lack of correlation between OFC and speed of processing may appear to be surprising because head growth is positively associated with neurodevelopmental scores of preterm infants at $\geq 18$ mo CGA (10). However, OFC is a marker of nutritional status in infants and children who are typically nutritionally deficient enough that they are at risk for microcephaly. The aggressive nutrition support in our population of infants resulted in little protein or caloric intake deficit and in head sparing overall, a finding supported additionally by the $z$-scores at each visit. Moreover, this study is unique in that it assesses specific at-risk neural processes, not gross neurodevelopment, and evaluates development earlier in infancy than other studies. These two factors allow us to link the brain and body composition findings with greater assurance. Finally, speed of processing is related to not only neuronal size, complexity, and number but also synapse and neurotransmitter number, which may not be reflected by OFC.

When CGA at visit and birth GA were added as covariates (Models 2 and 3), the $r^{2}$ values remained in the $45-60 \%$ range. CGA at visit was added as a covariate in Model 2 to account for variation in the timing of each visit (visit 2 , in particular, had nearly a 6-wk range in CGA at visit) because the VEP latency can mature up to $10 \mathrm{~ms} /$ week in the first months of life (18). In spite of this, as seen in the comparison of Model 1 and Model 2, CGA at visit did not have a significant effect on the association between FFM, weight, and length and the speed of processing. Birth GA was added in Model 3 to account for the possible influence that extreme prematurity and consequently longer "visual experience" may have on the maturation of the visual system. However, the effect of birth GA was not significant. Therefore, birth GA and CGA at visit do not play a significant role in the VEP latency in this study.

Our finding that the VEP latencies of formerly preterm infant females were faster than those of males is in concordance with a study by Malcolm et al., which showed the same sex-related differences in VEP latencies in healthy term newborns (23). Their study evaluated VEPs at 50 and $66 \mathrm{wk}$ postconceptual age; our mean CGA at the time of the VEPs was $59 \mathrm{wk}$, all well beyond term equivalent age. Of note, studies in older children and adults show that females have a lower proportion of white matter to gray matter compared with males $(24,25)$, which would seem to contradict these findings. However, VEPs in adults do not show sex differences in latencies (26). Therefore, 
although white matter is one component of neuronal processing speed, synaptic connections play a significant role as well. The mechanism behind the difference in processing speed between males and females during infancy is unclear. As Malcolm et al. concluded, studies at younger CGAs, especially at preterm CGAs, would help elucidate whether the sex difference in VEP latency is due to a difference in the timing of onset or the rate of maturation of the VEP. Furthermore, studies in preterm infants at older CGAs could show if and when these infants mature to the $100 \mathrm{~ms}$ latency of adults, which happens by 6 mo of age in healthy term infants.

We found minimal association in our evaluation of the relationship of infant body composition with P100 peak amplitude. At visit 1, body fat percentage was associated with higher peak amplitude of P100 in the unadjusted model and also when sex and CGA at visit were added as covariates. This was not present at visit 2. It is possible that this correlation is spurious because so many variables can affect amplitude (skull and scalp thickness, amount of cortical activation, etc.) and because no consistent association was seen over time or in the other models.

We also evaluated several clinical factors for their association with speed of processing. Hospital caloric deficit was negatively associated with P100 latency (higher deficit is associated with shorter (i.e., faster) latency). This was not anticipated because we expected that early nutritional deficits in neonates would not only negatively affect body composition but also play a negative role in brain development. However, this was in general a healthy population of preterm infants. The mean energy deficit was only $94 \mathrm{kcal} / \mathrm{kg}$ (equivalent to a deficit of less than a day's worth of energy for the entire hospitalization using a goal of $120 \mathrm{kcal} / \mathrm{kg} / \mathrm{d}$ ). A more significant deficit may be needed to observe a negative effect on speed of processing.

SNAP was not associated with speed of processing at 4 mo CGA. This was also unexpected because increased illness is often associated with poorer nutritional status (27). However, SNAP value is a calculation of illness severity in a single $24-\mathrm{h}$ period and may not be representative of overall postnatal illness. Other markers, such as steroid exposure and ROP, are probably better markers of overall long-term illness.

Our study found that postnatal steroid exposure and ROP were associated with longer P100 latency. It is difficult to say which factor, or both, drove this association because three out of the four infants with ROP were also infants who received postnatal steroids. ROP (grouped by worst stage documented) has been shown to correlate with longer VEP latency at $7 \mathrm{y}$ of age (28), and postnatal steroids affect neurodevelopmental outcomes (29). However, ROP and corticosteroid exposure may serve as biomarkers of illness because these were probably some of the sickest infants of the group. Neonatal illness is associated with not only nutritional deficiencies such as reduced protein intake (27) but also less protein accretion irrespective of nutrient intake. For example, exogenous steroids for chronic lung disease reduce protein accretion through increased proteolysis, although protein synthesis remains largely unchanged (30). A study with a larger sample size and more variation in these variables is needed to resolve the independent roles of illness and steroid treatment in speed of processing.

This study's limitations include the relative healthiness of the group and small sample size. The infants with acceptable VEP data were smaller and earlier in gestation than the 10 infants that were excluded, making them potentially at higher risk for neurodevelopmental abnormalities. Although the group of included infants was quite varied with reference to GA and size, the magnitude of the associations between FFM and latency observed in this analysis may be upwardly biased compared with what would be seen in a more diverse, general population of preterm infants. Future studies with a larger sample size, allowing for subanalysis of groups based on birth weight or GA, may help to better describe the effects of early GA. Because using the PEA POD for body composition assessment requires the infant to be in room air for at least $5 \mathrm{~min}$ at term CGA, we were unable to include the sickest of infants who were still requiring respiratory support at term. These sicker infants are more likely to have nutritional deficits (27) and long-standing inflammation and thus may have increased linear stunting and decreased FFM. Studies aimed at evaluating this subgroup of preterm infants would help clarify the role of illness in neurodevelopment and brain maturation.

The brain's "growth spurt" begins around midgestation and continues into the second postnatal year, throughout which there is a "tremendous increase in dendritic complexity accompanied by the establishment of synaptic connectivity (31)." This study shows the association of altered body composition in the neonatal period on brain development up to 4 mo CGA. It is unclear if the effects of abnormal body composition in preterm infants can be overcome by catch-up growth during the first years of life when continued complex brain development occurs. Furthermore, electrophysiologic studies evaluating brain development in this population longitudinally would be beneficial.

\section{CONCLUSION}

Our preliminary study shows that body composition variation in preterm infants, specifically lower FFM, is associated with slower speed of processing at 4 mo CGA, independent of sex, GA at visit, and GA at birth. FFM indexes organ growth and development and may be an important biomarker to follow in preterm infants to predict cognitive outcomes.

\section{METHODS}

\section{Subjects}

Participants in this study were recruited from the University of Minnesota Amplatz Children's Hospital neonatal intensive care unit from December 2008 to October 2009 with approval from the Institutional Review Board at the University Of Minnesota. Participants' parents provided written consent.

Inclusion criteria included infants born at a GA $<35 \mathrm{wk}$ and appropriate-for-GA birth weight. Exclusion criteria included weight $<1 \mathrm{~kg}$ or $>8 \mathrm{~kg}$ at discharge (validated weight range for body composition assessment in the PEA POD (COSMED USA, Concord, CA)) and/or inability to lie supine in room air for $5 \mathrm{~min}$. Twenty-six infants met criteria and had parental consent for participation. 
Infants were seen at term (38-42 wk CGA) for body composition assessment and at 4 mo CGA (55-62 wk CGA) for both body composition assessment and evaluation of speed of neural processing as indexed by VEPs.

Several clinical factors were measured for each infant during hospitalization. Cumulative energy deficit was calculated by using a 120 $\mathrm{kcal} / \mathrm{kg} / \mathrm{d}$ goal and subtracting (or adding in the case of a surplus) the actual amount of energy received. Cumulative protein deficit was calculated using a $3.5 \mathrm{~g} / \mathrm{kg} / \mathrm{d}$ goal and subtracting (or adding in the case of a surplus) the actual amount of protein received. Illness severity on postnatal day 1 was calculated using SNAP, a cumulative score of multiple physiological markers of illness in neonates, in which a higher score indicates a greater degree of illness.

Several factors were obtained by self-report from the parents, including breastfeeding status at each visit (including exclusive or some breastfeeding) and parental age, race, and highest education achieved.

\section{Body Composition Assessment}

At each visit, body composition was assessed using air displacement plethysmography by the PEA POD. A detailed explanation of the PEA POD's design, operating principles, validation, and measurement procedures is presented elsewhere (32-36). The PEA POD uses the principles of whole-body densitometry to derive fat and FFM values using body density, fat mass density $(0.9007 \mathrm{~g} / \mathrm{ml})$, and known ageand sex-specific FFM density values (37); this technique has been validated in preterm infants (38). Using the integrated electronic scale of the PEA POD, a 20-s infant body mass measurement is followed by a 2 min infant body volume measurement in the test chamber. Body density is then computed from body mass and volume.

\section{VEP Measurement}

Infants were seated in a darkened room on a parent's lap during the recording. The visual stimulus was a pattern-reversing black-and-white checkerboard, presented by E-Prime software (Psychology Software Tools, Sharpsburg, PA) with two reversals per second, displayed on a 20" ViewSonic Graphics Series G225f monitor (ViewSonic, Walnut, CA) for a total of 50 trials (39). Individual checks measured $\sim 1.5 \times 1.5 \mathrm{~cm}$ $\left(1.4 \times 1.4^{\circ}\right)$ and the monitor screen was $39 \mathrm{~cm}$ wide $\times 29 \mathrm{~cm}$ tall so that the visual field subtended to $33.4 \times 23.5^{\circ}$ at a viewing distance of $60 \mathrm{~cm}$. Attention to the screen was monitored through remote video system and the protocol was paused until attention was regained if there was a distraction. A research assistant was hidden behind the monitor by a cloth screen and provided auditory stimuli (squeak toy) to keep the infants' attention on the monitor (18). Pattern-reversal VEPs were recorded from ongoing EEG using the Geodesic EEG System 300 (Electrical Geodesics, Eugene, OR). Sixty-four channel sensor nets are designed in a "geodesic" pattern, with a specific electrode placed at the vertex, allowing for consistent placement of the electrodes on the scalp of each infant. Using NetStation 4.4.2 software (Electrical Geodesics), scalp impedances were measured and accepted if $<50 \mathrm{~K} \Omega$. EEG was referenced to the vertex, amplified with a 0.1 - to $100-\mathrm{Hz}$ bandpass and digitized at $250 \mathrm{~Hz}$.

\section{Data Analysis}

Data were analyzed offline using NetStation 4.4.2 analysis software (Electrical Geodesics). Data were filtered with a $30-\mathrm{Hz}$ lowpass filter, segmented to $500-\mathrm{ms}$ periods starting $100 \mathrm{~ms}$ before stimulus presentation, and baseline corrected to the average prestimulus voltage. EEGs were edited by hand for movement artifact, eye movement,

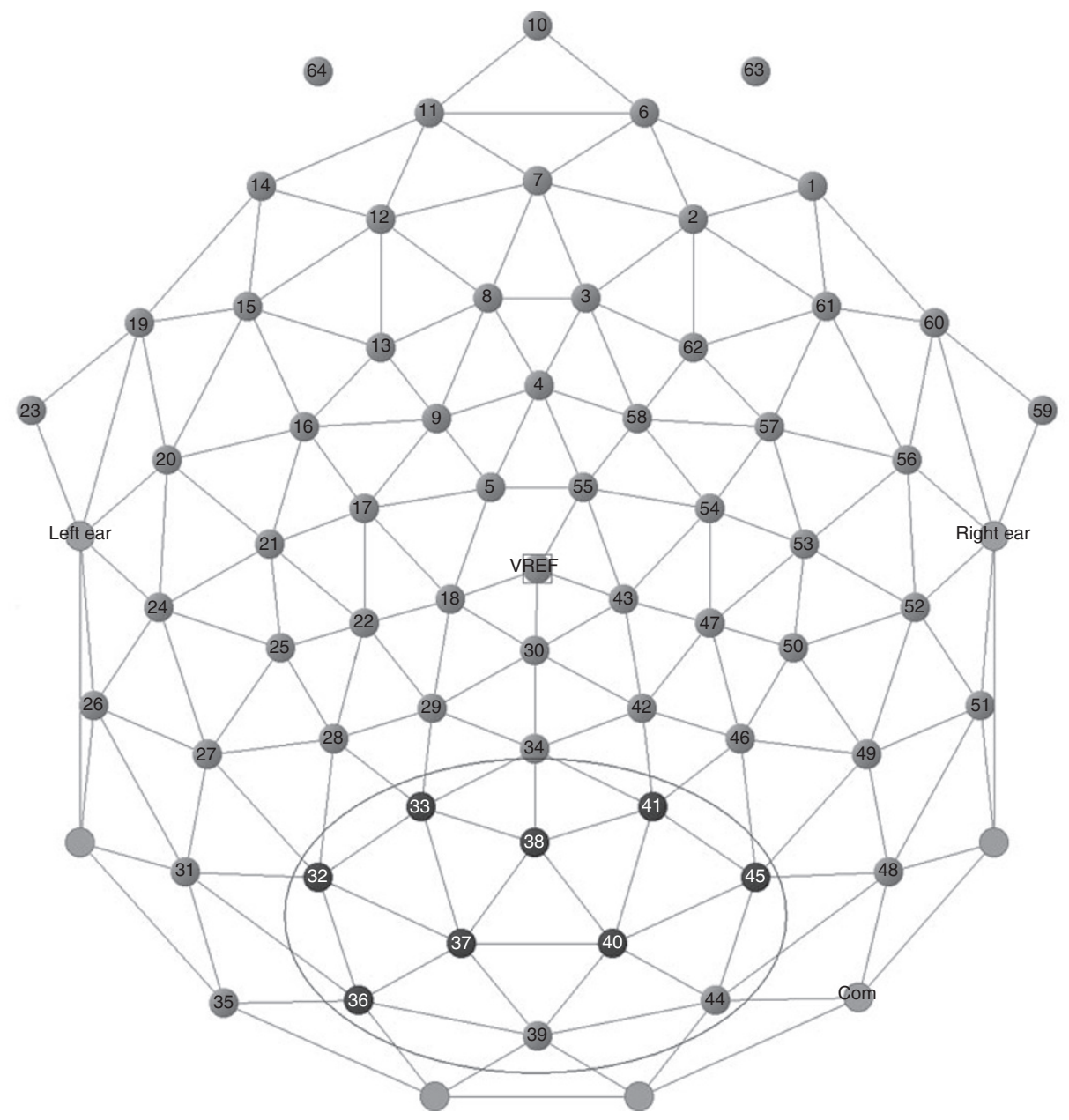

Figure 2. A schematic diagram of the 64-channel sensor net (Electrical Geodesics, Eugene, OR) and the occipital cluster of electrodes used for data analysis. Sensors that had adequate data for averaging are darkened. 
or poor recordings. Trials were excluded if the number of channels rejected was $>16 \%$; for the remaining trials, channels with bad data were replaced using spherical spline interpolation. Participants with $<12$ good trials were excluded from further analysis (mean number of good trials: 24 , range: $12-33$ ). For each remaining infant, the average waveform at each electrode was calculated and re-referenced to the average reference. Latency to the peak of the P100 component was derived from a $90-220 \mathrm{~ms}$ poststimulus window. When no P100 was identifiable in an individual lead, data were treated as missing in that infant. We analyzed the mean data from an occipital cluster of electrodes (Figure 2). If an electrode site within the cluster had missing data from more than two participants, that electrode site was not included in the mean. Thus, electrode sites included in the mean were 32, 33, 36, 37, 38, 40, 41, and 45 (Figure 2).

Differences between the group of infants who had acceptable VEP data and those with inadequate VEP data were evaluated using the Student's $t$ test (continuous data) and Fisher's exact test (categorical data). Multiple regression analysis was performed to assess the relationship between body composition measurements and latency to the P100 peak or its amplitude. Covariates added were infant sex, GA at birth, and CGA at each visit. Parameter estimates with standard errors and $P$ values were calculated. General linear models were used to generate least squared mean estimates and standard errors. The associations between various clinical factors (caloric deficit, protein deficit, and illness severity) and latency to the P100 peak were assessed using partial correlation coefficients. Student's $t$-test was also used to evaluate whether exposure to breast milk, steroids, ROP, or abnormal neuroimaging (intraventricular hemorrhage or periventricular leukomalacia) was associated with P100 latency.

All tests were performed with SAS 9.2 (SAS Institute, Cary, NC), with statistical significance defined at $P<0.05$.

\section{STATEMENT OF FINANCIAL SUPPORT}

Ellen Demerath has received grant funding from COSMED (Concord, CA), manufacturer of the PEA POD.

\section{REFERENCES}

1. Franz AR, Pohlandt F, Bode H, et al. Intrauterine, early neonatal, and postdischarge growth and neurodevelopmental outcome at 5.4 years in extremely preterm infants after intensive neonatal nutritional support. Pediatrics 2009;123:e101-9.

2. Ehrenkranz RA, Dusick AM, Vohr BR, Wright LL, Wrage LA, Poole WK. Growth in the neonatal intensive care unit influences neurodevelopmental and growth outcomes of extremely low birth weight infants. Pediatrics 2006;117:1253-61.

3. Ramel SE, Demerath EW, Gray HL, Younge N, Boys C, Georgieff MK. The relationship of poor linear growth velocity with neonatal illness and twoyear neurodevelopment in preterm infants. Neonatology 2012;102:19-24.

4. Hack M, Breslau N, Weissman B, Aram D, Klein N, Borawski E. Effect of very low birth weight and subnormal head size on cognitive abilities at school age. N Engl J Med 1991;325:231-7.

5. Latal-Hajnal B, von Siebenthal K, Kovari H, Bucher HU, Largo RH. Postnatal growth in VLBW infants: significant association with neurodevelopmental outcome. J Pediatr 2003;143:163-70.

6. American Academy of Pediatrics, Committee on Nutrition. Nutritional needs of preterm infants. In: Kleinman R, ed. Pediatric Nutrition Handbook, 5th edn. Elk Grove Village, IL: American Academy of Pediatrics, 2004:23-55.

7. Wilson DC, Cairns P, Halliday HL, Reid M, McClure G, Dodge JA. Randomised controlled trial of an aggressive nutritional regimen in sick very low birthweight infants. Arch Dis Child Fetal Neonatal Ed 1997;77:F4-11.

8. Ramel SE, Gray HL, Ode KL, Younge N, Georgieff MK, Demerath EW. Body composition changes in preterm infants following hospital discharge: comparison with term infants. J Pediatr Gastroenterol Nutr 2011;53:333-8.

9. Johnson MJ, Wootton SA, Leaf AA, Jackson AA. Preterm birth and body composition at term equivalent age: a systematic review and meta-analysis. Pediatrics 2012;130:e640-9.

10. Belfort MB, Rifas-Shiman SL, Sullivan T, et al. Infant growth before and after term: effects on neurodevelopment in preterm infants. Pediatrics 2011;128:e899-906.
11. Skullerud K. Variations in the size of the human brain. Influence of age, sex, body length, body mass index, alcoholism, Alzheimer changes, and cerebral atherosclerosis. Acta Neurol Scand 1985;102: Suppl c:194.

12. Forbes GB. Relation of lean body mass to height in children and adolescents. Pediatr Res 1972;6:32-7.

13. Fuglestad A, Rao R, Georgieff M. The role of nutrition in cognitive development. In: Nelson CA, Luciana L, eds. Handbook of Developmental Cognitive Neuroscience. 2nd edn. Cambridge, MA: MIT Press, 2008:623-42.

14. Can E, Bülbül A, Uslu S, Cömert S, Bolat F, Nuhoglu A. Effects of aggressive parenteral nutrition on growth and clinical outcome in preterm infants. Pediatr Int 2012;54:869-74.

15. Stephens BE, Walden RV, Gargus RA, et al. First-week protein and energy intakes are associated with 18-month developmental outcomes in extremely low birth weight infants. Pediatrics 2009;123:1337-43.

16. Johnson DE, Guthrie D, Smyke AT, et al. Growth and associations between auxology, caregiving environment, and cognition in socially deprived Romanian children randomized to foster vs ongoing institutional care. Arch Pediatr Adolesc Med 2010;164:507-16.

17. Dewey KG, Begum K. Long-term consequences of stunting in early life. Matern Child Nutr 2011;7 Suppl 3:5-18.

18. McCullough DL. Visual evoked potentials in infants. In: de Haan M, ed. Infant EEG and Event-related Potentials. London, UK: Psychology Press, 2007:41-76.

19. Ketelslegers JM, Maiter D, Maes M, Underwood LE, Thissen JP. Nutritional regulation of insulin-like growth factor-I. Metab Clin Exp 1995;44(10 Suppl 4):50-7.

20. Shambaugh GE 3rd, Natarajan N, Davenport ML, Oehler D, Unterman T. Nutritional insult and recovery in the neonatal rat cerebellum: insulin-like growth factors (IGFs) and their binding proteins (IGFBPs). Neurochem Res 1995;20:475-90.

21. Fretham SJ, Carlson ES, Georgieff MK. The role of iron in learning and memory. Adv Nutr 2011;2:112-21.

22. Poindexter BB, Denne SC. Protein needs of the preterm infant. Neoreviews 2003;4:e52-9.

23. Malcolm CA, McCulloch DL, Shepherd AJ. Pattern-reversal visual evoked potentials in infants: gender differences during early visual maturation. Dev Med Child Neurol 2002;44:345-51.

24. Schmithorst VJ, Holland SK, Dardzinski BJ. Developmental differences in white matter architecture between boys and girls. Hum Brain Mapp 2008;29:696-710.

25. Salinas J, Mills ED, Conrad AL, Koscik T, Andreasen NC, Nopoulos P. Sex differences in parietal lobe structure and development. Gend Med 2012;9:44-55.

26. Mitchell KW, Howe JW, Spencer SR. Visual evoked potentials in the older population: age and gender effects. Clin Phys Physiol Meas 1987;8:317-24.

27. Clark RH, Thomas P, Peabody J. Extrauterine growth restriction remains a serious problem in prematurely born neonates. Pediatrics 2003;111(5 Pt 1):986-90.

28. Mintz-Hittner HA, Prager TC, Schweitzer FC, Kretzer FL. The pattern visual-evoked potential in former preterm infants with retinopathy of prematurity. Ophthalmology 1994;101:27-34.

29. Wilson-Costello D, Walsh MC, Langer JC, et al.; Eunice Kennedy Shriver National Institute of Child Health and Human Development Neonatal Research Network. Impact of postnatal corticosteroid use on neurodevelopment at 18 to 22 months' adjusted age: effects of dose, timing, and risk of bronchopulmonary dysplasia in extremely low birth weight infants. Pediatrics 2009;123:e430-7.

30. Van Goudoever JB, Wattimena JD, Carnielli VP, Sulkers EJ, Degenhart HJ, Sauer PJ. Effect of dexamethasone on protein metabolism in infants with bronchopulmonary dysplasia. J Pediatr 1994;124:112-8.

31. Dobbing J, Sands J. Quantitative growth and development of human brain. Arch Dis Child 1973;48:757-67.

32. Urlando A, Dempster P, Aitkens S. A new air displacement plethysmograph for the measurement of body composition in infants. Pediatr Res 2003;53:486-92.

33. Sainz RD, Urlando A. Evaluation of a new pediatric air-displacement plethysmograph for body-composition assessment by means of chemical analysis of bovine tissue phantoms. Am J Clin Nutr 2003;77:364-70. 
34. Yao M, Nommsen-Rivers L, Dewey K, Urlando A. Preliminary evaluation of a new pediatric air displacement plethysmograph for body composition assessment in infants. Acta Diabetol 2003;40 Suppl 1:S55-8.

35. Ma G, Yao M, Liu Y, et al. Validation of a new pediatric air-displacement plethysmograph for assessing body composition in infants. Am J Clin Nutr 2004;79:653-60.

36. Ellis KJ, Yao M, Shypailo RJ, Urlando A, Wong WW, Heird WC. Bodycomposition assessment in infancy: air-displacement plethysmography compared with a reference 4-compartment model. Am J Clin Nutr 2007;85:90-5.
37. Fomon SJ, Haschke F, Ziegler EE, Nelson SE. Body composition of reference children from birth to age 10 years. Am J Clin Nutr 1982;35 (5 Suppl):1169-75.

38. Roggero P, Giannì ML, Amato O, et al. Evaluation of air-displacement plethysmography for body composition assessment in preterm infants. Pediatr Res 2012;72:316-20.

39. Benedict L, Nelson CA, Schunk E, Sullwold K, Seaquist ER. Effect of insulin on the brain activity obtained during visual and memory tasks in healthy human subjects. Neuroendocrinology 2006;83: $20-6$. 